\title{
SC|A2
}

Edúcaçã̃o, Comunicação e Tecnologia

\section{Mulher, Mãe, Professora e Pesquisadora em Tempos de Pandemia: mas, esta história nem sempre foi assim...}

Bianca de Macedo Abreu ${ }^{1}$

\section{Resumo}

Neste trabalho trataremos da multiplicidade do ser mulher e da diversidade de funções desempenhadas por ela em seu cotidiano em tempos de pandemia,da rotina alterada e intensificada da mulher como mãe, companheira, dona de casa, profissional, estudante e pesquisadora. À luz de Boaventura, abordaremos a invisibilidade do vírus, as mudanças e situação da mulher ainda como uma classe discriminada, à margem da sociedade. Com base nos princípios de Foucault,falaremos desta relação de poder e saber, desta batalha da independência e respeito, que ainda estão em processo, mas com avanços ao longo do tempo. Portanto, este texto tem a centralidade na mulher, valorizando sua história de luta por igualdade social que permite reconhecimento dos diversos papéis concomitantes exercidos por ela nos dias atuais, ecoando sua voz nas casas, famílias, trabalhos e até em cargos de maior poder de um país. A principal contribuição desse texto é evidenciar a força da mulher em diferentes espaços de participação na sociedade.

\section{Palavras-chave}

Mulheres. Pandemia. Cotidiano. Igualdade social.

Recebido em: 29/07/2020

Aprovado em: 22/12/2020

1 Mestranda do departamento de Educação, na área de Processos Formativos e Desigualdades Sociais (PPG-EDU) da Faculdade de Formação de Professores de São Gonçalo (FFP) da Universidade do Estado do Rio de Janeiro (UERJ). Assessora Pedagógica da Subsecretaria de Educação de Niterói/RJ (SEMECT/FME) e Professora de Inglês da Secretaria de Educação do Estado do Rio de Janeiro (SEEDUC).

E-mail: biamacedoabreu24@gmail.com 


\section{Woman, Mother, Teacher and Researcher in Times of Pandemic: but, this story was not always like this...}

\section{Abstract}

In this paper we will deal with the multiplicity of being a woman and the diversity of functions performed by her in her daily life in times of pandemic, the altered and intensified routine of women as mothers, companions, housewives, professionals, students and researchers. The research will be based on the pandemic by Boaventura, we will address the invisibility of the virus, the changes and the situation of women as a discriminated class, on the margins of society. Based on Foucault's principles, we will talk about this relationship of power and knowledge, of this battle for independence and respect, which are still in process, but with many advances over time. Therefore, this text is centered on women, valuing their history of struggle for social equality that allows recognition to the various concomitant roles played by her today, echoing her voice in homes, families, jobs and even in the positions of greater power of a country. The main contribution of this text is to highlight the strength of women in different spaces of participation in society.

\section{Keywords}

Women. Pandemic. Daily Life. Social Equality. 


\title{
Introdução
}

A música Mulher, composta e cantada por Erasmo Carlos, começa assim: "Dizem que a mulher é o sexo frágil, mas que mentira absurda! Eu que faço parte da rotina de uma delas, sei que a força está com elas...”. Nesta canção o autor reconhece a versatilidadee o empoderamento das mulheres, e suas múltiplas funções no cotidiano de cada uma delas. Portanto, com foco na mulher em tempos de pandemia, em um mundo globalizado, circundado de inovações tecnológicas, este texto narra experiências e vivências da mulher, autora deste artigo, nos âmbitos pessoal, profissional da educação, da pesquisa, da maternidade, dos trabalhos domésticos e da companheira/namorada/esposa. Esta multiplicidade de ações concomitantes gerenciadas pela mulher é oriunda de uma história de militância e conquistas por igualdade de condições e direitos de seu papel na sociedade. Para melhor entender este percurso, elencaremos algumas mulheres no decorrer do texto, evidenciando fatos que corroboraram nesta luta de valorização e independência da mulher, visto que nem sempre foi assim.

Boaventura coloca que "qualquer quarentena é sempre discriminatória, mais difícil para uns grupos sociais do que para outros e impossível para um vasto grupo de cuidadores, cuja missão é tornar possível a quarentena ao conjunto da população" (SANTOS, 2020, p.15). O autor insere as mulheres neste grupo pela vulnerabilidade social, política e cultural, e diz que,

\begin{abstract}
São elas que continuam a ter a seu cargo exclusiva ou majoritariamente, o cuidado das famílias. Poderia imaginar-se que, havendo mais braços em casa durante a quarentena, as tarefas poderiam ser mais distribuídas... Com as crianças e outros familiares em casa durante 24 horas, o stress será maior e certamente recairá mais nas mulheres. $\mathrm{O}$ aumento do número de divórcios em algumas cidades chinesas durante a quarentena pode ser um indicador do que acabo de dizer. Por outro lado, é sabido que a violência contra as mulheres tende a aumentar em tempos de guerra e de crise - e tem vindo a aumentar agora. Uma boa parte dessa violência ocorre no espaço doméstico. O confinamento das famílias em espaços exíguos e sem saída pode oferecer mais oportunidades para o exercício da violência contra as mulheres. (SANTOS, 2020, p.16)
\end{abstract}

Mesmo com a conquista, após fato ocorrido no Ceará com Maria da Penha, nome atribuído a Lei $\mathrm{n}^{0} 11.340 / 2006$, criada para combater a violência 
doméstica e familiar, garantindo maior rigorosidade na punição dos agressores e criando mecanismos para prevenir a violência e proteger a mulher agredida, ainda acompanhamos os noticiários com vários casos de agressões e feminicídios (crime de homicídio, Lei no 13.104/2015), inclusive no decorrer da pandemia como mencionou Boaventura. É um processo e temos muito a alcançar ainda.

Segundo Foucault existem “... três grandes sistemas de exclusão que atingem o discurso, a palavra proibida, a segregação da loucura e a vontade de verdade ...” (FOUCAULT, 1996, p.19). Fatos históricos evidenciam a exclusão da mulher nas relações de poder e saber, mas a eleição e reeleição direta de uma mulher para Presidência da República do Brasil, de Dilma Rousseff, iniciada em 2010, ocupando a autoridade máxima do executivo de um Estado, é um fato muito potente de ocupação deste lugar de poder. E entendendo estes discursos a partir das produções sociais, do poder e do saber contidos neles, selecionando os sujeitos que falam, no sentido de interdição, loucura e o que não é verdadeiro, é que colocamos a voz, a presença e a sabedoria do discurso da mulher, que permanece em luta pelo direito de ser ouvida e respeitada nos diversos níveis de relações sociais e políticas.

Vivemos em período pandêmico da COVID-19, logo, toda nossa rotina foi alterada e intensificada de atividades. Por isso, em minha residência, algumas tarefas foram dividas, mostrando a importância de cada um para mantermos a organização $\mathrm{e}$ atendermos às diversas demandas. $\mathrm{O}$ confinamento $\mathrm{e}$ a quantidade de notícias sobre a situação da pandemia no mundo nos trouxeram curiosidades e pesquisas sobre o vírus, e uma delas está descrita na reportagem da BBC a seguir.

O sars-cov-2, vírus que causa a covid-19, é um vírus novo, mas é do mesmo grupo do coronavírus identificado pela primeira vez pela pesquisadora June Almeida em 1964 em seu laboratório no hospital St. Thomas', em Londres.(BBC News Brasil, 2020)

Portanto, a mulher em destaque no cenário científico, ocupando espaço nesta relação de poder e saber, sobre uma questão muito presente nos dias atuais. Alguns detalhes desta descoberta, na qual uma mulher foi pioneira: 
Eles enviaram amostras para June Almeida, que viu as partículas virais. Ela descreveu como vírus influenza, mas não exatamente o mesmo - ela havia identificado o que ficou conhecido como o primeiro coronavírus humano. Winter diz que Almeida já havia visto partículas assim antes, enquanto pesquisava a hepatite de ratos e a bronquite infecciosa de galinhas.

No entanto, seu trabalho para uma revista científica havia sido rejeitado "porque os outros cientistas disseram que as imagens que ela produziu eram apenas imagens ruins de partículas do vírus influenza".

Mas a nova descoberta da cepa B814 foi publicada no British Medical Journal em 1965 e as primeiras fotografias do que ela viu foram publicadas no Journal of General Virology dois anos depois.

De acordo com Winter, foram Tyrrell e Almeida, juntamente com o professor Tony Waterson, diretor do St. Thomas', que nomearam os coronavírus por causa da coroa em torno da imagem viral.

Minha família tem, ou melhor, tinha uma vida social muito intensa (festas, encontro com amigos, entretenimento...) e com o isolamento social, estamos longe de nossos parentes próximos e amigos. Esta é uma das consequências ruins desta pandemia. Estamos felizes em nossa casa e sabemos que temos uma situação privilegiada, estável em relação ao grande número de pessoas desempregadas, em função da questão econômica proveniente de uma pandemia. Mesmo com o auxílio emergencial de $\mathrm{R} \$ 600,00$ dado pelo governo, com parcelas do FGTS, benefício emergencial, de R \$ 1.045,00, e outras medidas econômicas, políticas e sociais de outras esferas, a situação está difícil para muitos.

Para minimizar esta distância física, utilizamos a tecnologia, aprendemos a acessar novas plataformas de reunião/encontros. Desta forma, nos vemos e nos mantemos conectados de alguma forma, através dos ambientes virtuais e telefone. Até os mais resistentes, alguns de uma geração anterior àminha, aprenderam os mecanismos, os recursos tecnológicos e aderiram às redes sociais, comprovando assim as oportunidades através da excepcionalidade deste momento. Outro ponto são as lives que nos aproximam do universo cultural, artístico e também enriquecem nossa formação profissional. No entanto, são tantas que temos que selecionar de acordo com o grau de relevância e a disponibilidade de nossos horários, tão ocupados de tarefas. E a resistência à 
tecnologia, provavelmente será menor, assim como as novas possibilidades de comunicação e trabalho após esta pandemia.

Em quarentena, esta mudança no cotidiano trouxe uma série de reflexões, pois apesar da consternação por tantas vidas perdidas, em virtude do COVID-19, do medo e da angústia deste "inimigo" invisível, a pandemia está sendo um tempo de oportunidades e aprendizados.

Boaventura discorre sobre a trágica transparência do vírus e diz que

O sentido literal da pandemia do coronavírus é o medo caótico generalizado e a morte sem fronteiras causados por um inimigo invisível...O invisível todo-poderoso tanto pode ser o infinitamente grande (o deus das religiões do livro) como o infinitamente pequeno (o vírus).(SANTOS,2020, p.10)

O autor faz uma comparação do invisível, mas com graus diferentes, fazendo um paralelo entre a religião e a ciência. Até a modernidade, os conhecimentos considerados válidos eram ligados à religião ou por alguns filósofos que explicavam a formação do mundo através da força da natureza. E de acordo comos conhecimentos vinculados à religião, na Bíblia, em Gênesis 2, aparece a criação da mulher, a Eva, nesta concepção.

Com a costela que havia tirado do homem, o Senhor Deus fez uma mulher e a levou até ele.

Disse então o homem:

"Esta, sim, é osso dos meus ossos

e carne da minha carne!

Ela será chamada mulher, porque do homem foi tirada".

Por essa razão, o homem deixará pai e mãe e se unirá à sua mulher, e eles se tornarão uma só carne.

O homem e sua mulher viviam nus, e não sentiam vergonha.

Na origem bíblica, a mulher foi tirada do homem, logo uma das interpretações possíveis é a ideia de pertencimento a este homem, de certa obediência. Boaventura (2008) aborda o conhecimento científico, tão evidenciado e relevante quanto à importância das pesquisas neste momento de pandemia e para o desenvolvimento mundial, mas também menciona o senso comum, ou seja, conhecimentos produzidos no cotidiano que não são tidos como válidos. Enfim, para o conhecimento científico, a origem do homem/ mulher tem uma concepção diferente da religiosa. 
Tanto na concepção da ciência quanto da fé, para os que acreditam, podemos destacar as múltiplas facetas da mulher neste "novo normal", com narrativas da minha história de vida como mulher mãe, profissional, pesquisadora, companheira e dona de casa. Para estabelecer este panorama da mulher no século XXI, em meio à pandemia, seguem citações de fatos históricos que demonstram as conquistas, para o reconhecimento destas ocupações simultâneas, que dinamizam o cotidiano hoje de forma muito intensa, mesmo com uma rotina estruturada e reestruturada, conforme as necessidades.

\section{Mulher Mãe}

Comecei esta multiplicidade de funções exercidas pela mulher, pela maternidade, que me completou como mulher, dando inteireza ao meu ser. Escolhi ser mãe. É muito bom ter este poder de escolha, pois nem sempre foi assim. Um marco para esta autonomia foi a chegada da pílula anticoncepcional ao mercado, em 1960. Leila Diniz foi uma mulher símbolo de liberdade e beleza da gravidez, exibindo, orgulhosamente sua barriga de grávida com biquíni, na praia de Ipanema, em 1970. Uma de suas frases é "sobre minha vida, meu modo de viver, não faço o menor segredo. Sou uma moça livre." (E-BIOGRAFIA, 2020)

Mas, na história, pior que não ter direito a esta decisão de engravidar ou não, é não poder ficar com seu filho/a como acontecia no sistema escravocrata que "se encarregava de não permitir que a 'família negra' se constituísse, fragmentando o elo parental básico, distanciando os filhos dos pais"(FARIAS, 2005, p.42). Como mãe, ser apartada de seu/sua filho/a é uma crueldade imensurável. A mulher negra tinha que deixar seu filho/a recém-nascido/a para ser ama de leite do filho/a da "senhora da casa-grande", e em muitos casos as crianças eram vendidas e as mães não as viam mais. Embora as desigualdades sociais aconteçam ainda hoje, as circunstâncias são outras. Existem leis que garantem este convívio das mães com seus/suas pequenos/as, da mesma forma que incentivam o aleitamento materno. Mais uma conquista das mulheres e uma reflexão para aproveitar este laço maternal para as mulheres que almejam isso. 
Sou mãe de uma criançaque fez 7 anos durante a pandemia, e de outra que foi um presente da vida, minha ex-aluna, hoje com 29 anos.A pequena está no Ensino Fundamental, tem aulas online, de forma síncrona, um tempo de manhã e outro à tarde, e precisa do acompanhamento de um responsável. Mas especificamente, como sou professora, realizo um atendimento educacional especializado com ela, por ter descoberto a dificuldade com leitura (dislexia) que demanda um tempo maior para realização das atividades, além do acompanhamento nos encontros online com fonoaudióloga. O levantamento desta hipótese foi feito por mim durante a pandemia. Oportunidades deste momento pandêmico. Logo, foi necessário estabelecer uma rotina para criança e para mãe acompanharem e realizarem as atividades do cotidiano. A filha maior está no segundo curso de Graduação, na Universidade Federal Fluminense (UFF), que ama loucamente, faz parte de grupos de pesquisa, é assistente de pesquisa do laboratório de pesquisa, produção e análise da imagem (L'image/CNPq), é bolsista do Pró-reitora de assuntos estudantis (PROAES/UFF). Com toda esta programação acadêmica, ela fica online de forma síncrona e assíncrona boa parte do dia e das madrugadas. Grande parte do meu dia é destinada exclusivamente a mulher mãe, os outros compromissos acontecem nestes intervalos.

A quarentena oportunizou acompanhá-las mais de perto no dia a dia. Este foi um lado positivo deste período. Tive tempo para: ver os dentes permanentes superiores crescerem da menor; para brincar com minha boneca de boneca;brincar com os brinquedos para criar muitas brincadeiras, nas quais embarcamos neste mundo de faz de conta; inserir e insistir na variedade de alimentos nas refeições diárias; direcionar práticas pedagógicas para apoio educacional no processo de leitura e escrita; continuar com o trabalho para formação leitora, muitas histórias para contar. De acordo com as autorasabaixo, contemplar

[...]espaços e momentos com diferentes dinâmicas e ritmos, com características da vida cotidiana das crianças, valorizando assim, brincadeiras, materiais e fazeres, de seus grupos de origem, num ambiente prazeroso e lúdico. Tais atividades devem visar a interação entre as áreas de conhecimento e aspectos da vida cidadã. (AQUINO; VASCONCELLOS, 2005, p.113) 
Quando necessito ocupar outras funções, aproveito o horário que a menor está dormindo, logo acordo mais cedo e durmo mais tarde. $\mathrm{E}$ às vezes durante o dia, lanço mãos de recursos tecnológicos (televisão, celular, vídeos, músicas ...), de forma moderada, para o entretenimento da criança enquanto estou em outras atividades concomitantes.

\section{Mulher Profissional}

Eu tive exemplos de mulheres fortes como a minha mãe, que começou a trabalhar com 11 anos, era uma espetacular professora e me mostrou a importância de ter uma profissão. Ela sempre falava da sua admiração pela sua avó Maricota, no caso minha bisavó, que era negra, filha de escrava com o senhor da casa grande. Por este motivo, teve "privilégios", sendo criada dentro de casa, com estudo se formou como professora primária, falava francês e tocava piano. Ela e minha mãe trocavam várias práticas pedagógicas e percebiam a diferença do processo ensino-aprendizagem com o decorrer do tempo. Para ilustrar, minha bisavó achava um absurdo minha mãe não "saber de có” os rios do Brasil e seus afluentes. Minha mãe achava graça desta cobrança.

Escolhi minha profissão, sou professora, gosto do que faço, procuro me manter atualizada e tenho independência financeira. Trabalho nas redes públicas de Educação, há 28 anos, com a Educação Básica. Em uma estou como professora da sala de recursos atendendo alunos do Fundamental II e Ensino Médio, de 4 escolas diferentes. Na outra estou como assessora pedagógica da Subsecretaria de Educação. Nesta última, com todos os cuidados, continuamos a trabalhar presencialmente para atender as demandas.

Embora tenha experiências com a Educação a Distância (EaD), com a Educação Online, síncrona, estou me familiarizando. Há pelas esferas governamentais um repensar diário em como garantir o calendário escolar e uma educação de qualidade. De acordo com a autora Edméa,

A educação de qualidade independe da modalidade. É possível ter educação de qualidade presencial, a distância, online e em desenhos híbridos. Contudo, o exercício de distinguir e caracterizar cada modalidade educacional nos habilita a dizer 
de que lugar falamos ou defendemos nossas ideias. (SANTOS, 2009, p. 5667).

Durante a pandemia, houve o cuidado em manter a interação, estabelecendo assim, vínculo com estudantes. No entanto, encontrei uns obstáculos, por parte da maioria dos discentes em relação aos suportes tecnológicos, como equipamentos eletrônicos e acesso à internet, para estabelecer a interatividade e acessar as atividades disponibilizadas nos ambientes virtuais. A exclusão digital é um desdobramento da exclusão social, logo uma questão de políticas públicas. Enfim, há uma diversidade de singularidades que requerem um olhar diferenciado para cada caso, "a educação online é o conjunto de ações de ensino-aprendizagem ou atos de currículo mediados por interfaces digitais que potencializam práticas comunicacionais interativas e hipertextuais" (SANTOS, 2009, p. 5663). Mas, para acompanhar os estudos no formato da educação online é preciso ter recurso tecnológico, acessibilidade e disponibilidade.

Como professora, mesmo com toda organização e planejamento, não há um espaço em minha residência com privacidade para as atividades laborais, logo quando os encontros acontecem, eles vêm acompanhados de surpresas como ruídos internos (panela cai, campainha toca, filho que chora...) ou externos à casa (moto que passa, vizinho que grita, ...), as filhas aparecem no fundo ou na tela junto comigo, e assim por diante. Contudo, com todos os contratempos advindos deste contexto, conseguimos alcançar nossos objetivos e a cada dia encontramos recursos tecnológicos para dar um retorno mais rápido ao aluno. No entanto, temos o desafio constante de aprender as técnicas mais avançadas para as aulas neste período de excepcionalidade.

\section{Mulher Companheira / Namorada / Esposa}

A melhor companheira da mulher é ela mesma, é enamorar-se por si mesma. Mas, nem sempre foi assim. Em fatos históricos podemos observar a falta de independência da mulher, a submissão dela, como a questão do casamento na qual a mulher não podia escolher o seu companheiro, e em alguns casos só o conhecia próximo à celebração. Depois tinha que se submeter aos desejos do marido, sendo a procriadora. Podemos exemplificar com a vida do casal 
imperial, através do enlace matrimonial da princesa Leopoldina, no século XIX, quando

Resolveu a arquiduquesa austríaca casar espontaneamente com D. Pedro por saber que este casamento era do agrado do pai e por acreditar, de acordo com a sua educação, que o cumprimento do desejo paterno não podia deixar de ter a bênção de Deus. (OBERACKER JR., 1977, p. 391).

Hoje, podemos escolher o tipo de relação que queremos, a opção sexual e o/a parceiro/a, apesar da discriminação ainda existente, houve grandes conquistas de liberdade e independência.

Embora eu tenha aprendido que sou uma excelente companhia para mim, também gosto de compartilhar a vida com um parceiro, amigo, que divide as atribuições, alegrias, tristezas e viagens, mas a quem tenho que dar atenção da mesma forma com que pretendo receber. Logo, este compartilhamento de vivências e afeto também faz parte da minha rotina, e na quarentena o convívio ficou mais intenso, e ainda melhor. Ah... o amor!

\section{Mulher Dona de Casa}

Fazer atividades domésticas, de forma geral, não fazia parte da minha rotina, mas durante a pandemia: lavei, passei, arrumei, limpei, cozinhei, e uma lista infindável de ações como a louça que nunca termina na pia. Porém, mesmo estabelecendo atribuições para todos, é pesado. Mas nem sempre foi assim.

No Brasil escravocrata, a família patriarcal era modelo essencial da sociedade. As relações familiares são fortemente determinadas por um sistema piramidal: o homem, o pai, o chefe, está no topo, sendo-lhe atribuída uma autoridade inflexível. (VASCONCELOS, 2005, p. 39).

E pensar que muitos falam que quem está em casa não trabalha, não reconhecendo a importância desta função. Hoje, em algumas famílias percebemos a divisão de tarefas, não tendo a separação das atividades femininas e masculinas. E sendo a limpeza condição básica de higiene e bem-estar, todo trabalho é feito com muito esmero. No entanto, na cozinha passei a ser "master chef", a fazer comidas deliciosas. O pessoal daqui de casa aprovou os pratos e todo mundo engordou. Este foi um ponto ruim da quarentena. Portanto, 
percebemos a necessidade de retornar às atividades físicas para manter o condicionamento e a saúde.

No início da pandemia com novos hábitos de higiene do cotidiano, fiquei um pouco neurótica, desinfetando maçanetas e interruptores, lavando tudo que vem da rua, passando pano no chão a toda hora, tirando roupas e calçados logo na entrada. Porém, com os cuidados intensificados, penso que as coisas já acontecem de forma mais natural, ou seja, o que era novo, já faz parte da rotina e de repente ficará em nossos hábitos, sendo um dos aprendizados deste momento para a vida.

\section{Mulher Pesquisadora}

Esta é minha mais nova escolha: ser pesquisadora. Este é um mundo desconhecido a ser desbravado. Quanto mais aprendemos, mais percebemos que temos a aprender, pois como diz Paulo Freire (2002) somos seres curiosos, inacabados, inconclusos, e isto é ótimo para buscar caminhos de conhecimentos. E a pesquisa segue também este trajeto de investigar e conhecer. Participo como orientanda do grupo de pesquisa com o tema Processos Formativos em Educação, e eu estou pesquisando sobre a formação do leitor, trabalhando com as narrativas de professores, a partir do conceito de experiência de Josso (2010).É o início de muitas outras.

\section{Algumas considerações}

Rancière (2005) coloca que não há hierarquia de inteligência e direciono esta igualdade ou possibilidade de saber ao ser humano, independente do gênero homem ou mulher. A partir deste princípio, reitero o poder dos discursos, pois muitas foram as lutas e conquistas das mulheres, e outras estão em processo. Esta versatilidade que oportuniza a realização de múltiplas funções só engrandece a figura feminina, mas tudo tem um limite, e o respeito ao fazer do outro é a base para articular qualquer situação.

Vivemos em um mundo globalizado, no qual a tecnologia está posta para ser usada a nosso favor, no qual as comunicações e as interações podem ser 
mantidas de forma virtual, independentes da distância. Claro, que com isso não estou dispensando aquele abraço de que estamos tão carentes, mas sim, evidenciando maneiras de superar este momento de excepcionalidade trazido pela pandemia do COVID-19.

Somos seres históricos sociais e somos história neste momento em que o mundo está confinado, aflito, assustado e dolorido pelas perdas, mas também acredito que como tudo na vida, tem pelo menos dois lados, o ruim, que já foi mencionado com as consequências da pandemia, e o bom, em decorrência das oportunidades e dos aprendizados inerentes ao período pandêmico, aproveitando assim o que ficará de positivo em nosso cotidiano, como: os conhecimentos tecnológicos; os hábitos mais rigorosos de higiene e saúde; a importância da interatividade social, de estar com o outro; a atenção ao meio ambiente, que comprovou sua capacidade regeneração em meio à destruição causada pelo ser humano e os animais retomando o seu habitat, e assim segue uma lista.

Acredito que é preciso esta predisposição para sentir, olhar e ver as transformações que aconteceram e acontecem conosco durante a pandemia, através destas vivências, pois como narra Josso (2010), se estas, poeticamente, nos atravessaram, no sentido de tornarem-se significativas, são experiências que podem ressignificar vidas, as vidas femininas que nem sempre foram importantes e visibilizadas.

\section{Referências}

AQUINO, Ligia Maria Leão de; VASCOCELlOS, Vera Maria Ramos de. Orientação Curricular para a Educação Infantil: referencial curricular nacional e diretrizes curriculares nacionais. In. VASCONCELLOS, Maria. R, de. (Org.). Educação da Infância: história e política. Rio de Janeiro, DP\&A, 2005.

BBC NEWS BRASIL. A cientista que descobriu o primeiro coronavírus humano - após ter abandonado escola aos 16 anos.Disponível em: jul de 2020.

$<$ https://www.bbc.com/portuguese/geral-52303032. $>$ Acesso em: $10 \mathrm{de}$

BIBLIAON, Bíblia Sagrada Online. Adão e Eva (episódio bíblico). Gênesis 2. Disponível em: <https://www.bibliaon.com/adao e eva/>. Acesso em 26 de jun. de 2020. 
E.BIOGRAFIA. Biografia Leila Diniz. Disponível em:

<https://www.ebiografia.com/leila diniz/\#: :text=Leila\%20Roque\%20Diniz\% 2onasceu\%20em,na\%20casa\%20de\%20uma\%20tia.>Acesso em: 26 de jun.

2020.

FARIAS, Mabel. Infância e educação no Brasil nascente. In. VASCONCELLOS, Maria. R, de. (Org.). Educação da Infância: história e política. Rio de Janeiro, DP\&A, 2005.

FOUCAULT, Michel. A ordem do discurso. Ed. Loyola, São Paulo, 3 a edição, 1996.

FREIRE, Paulo. Pedagogia da autonomia: saberes necessários à prática educativa. Ed. Paz e Terra, São Paulo, 25 a edição, 2002.

JOSSO, Marie-Christine. A experiência de vida e formação. 2. ed. rev. e ampl. Natal, RN, EDUFRN, São Paulo: Paulus, 2010.

OBERACKER JR, Carlos H. A Biografia da Imperatriz Leopoldina e a História do Brasil. Portal da Revista USP. v. 55 n. 110, São Paulo, 1977.

RANCIÈRE, Jacques. $O$ mestre ignorante: cinco lições sobre a emancipação intelectual. 2 ed. $-1^{\text {a }}$ reimp. Belo Horizonte: Autêntica, 2005.

SANTOS, Boaventura de Sousa. Um discurso sobre as ciências. 5. ed. - São Paulo, Cortez, 2008.

A Cruel Pedagogia do Vírus. Ed. Almedina S.A.

Coimbra, 2020.

SANTOS, Edméa. Educação online para além da EAD: um fenômeno da cibercultura. Actas do X Congresso Internacional Galego-Português de Psicopedagogia. Braga: Universidade do Minho, 2009 ISBN- 978-972-8746-711. Disponível em: <http://www.educacion.udc.es/grupos/gipdae/documentos/congreso/xcongres o/pdfs/t12/t12c427.pdf > Acesso em: 26 de jun. 2020. 